Revista Água Viva

ISSN 1678-7471

\title{
RETRATOS DE UMA CAPITAL EXCLUDENTE: A MODERNIDADE NO RIO DE JANEIRO EM TRÊS CRÔNICAS DE LIMA BARRETO
}

\section{PORTRAITS OF AN EXCLUDING CAPITAL: MODERNITY IN RIO DE JANEIRO IN THREE CHRONICLES OF LIMA BARRETO}

\author{
Jiliane Movio Santana ${ }^{1}$ \\ Marcelo Fernando de Lima²
}

Recebido em: 30 abr. 2020.

Aceito em: 24 nov. 2020.

DOI: 10.26512/aguaviva.v5i3.31257

RESUMO: O objetivo deste trabalho é analisar três crônicas de Lima Barreto publicadas em 1907, compreendidas aqui como narrativas históricas que versam sobre os impactos das transformações urbanas no Rio de Janeiro da Belle Époque tropical, higienista e excludente. Assim como em boa parte de sua obra, o autor apresenta nestes três textos uma linguagem crítica com utilização da sátira e da ironia para denunciar as desigualdades sociais vividas no Brasil dos primeiros anos do regime republicano. Com esta análise, nosso objetivo é mostrar o descompasso de um ideal de modernidade importado da Europa e a modernidade excludente, de aparências mas real, presente nas ruas da Capital Federal, satirizada na escrita rápida de Lima Barreto.

Palavras-chave: Literatura brasileira. História. Modernidade. Lima Barreto. Crônicas.

ABSTRACT: The objective of this work is to analyze three chronicles of Lima Barreto published in 1907, understood here as historical narratives that deal with the impacts of urban transformations in Rio de Janeiro during the tropical, hygienist and excluding Belle Époque. As in much of his work, the author presents in these three texts a critical language using satire and irony in order to denounce the social inequalities experienced in Brazil in the early years of the republican regime. With this analysis, our objective is to show the mismatch of an ideal of modernity imported from Europe and the exclusionary modernity, of appearances but real, present in the streets of the Federal Capital, satirized in Lima Barreto's speedy writing.

\footnotetext{
1 Mestranda do Programa de Pós-Graduação em Estudos de Linguagens (PPGEL), da Universidade Tecnológica Federal do Paraná (UTFPR). Graduada em Licenciatura Plena em História, pela Universidade Estadual Paulista, UNESP, campus Assis, em 2006. Especialista em Educação das Relações Étnico Raciais pela Universidade Federal de Ouro Preto/MG (programa UNIAFRO - 2015), em Educação pela Universidade Federal de Alfenas/MG (2015) e em Literatura Brasileira e História Nacional pela Universidade Tecnológica Federal do Paraná (UTFPR em 2019). E-mail: jiliane.movio@gmail.com

2 Doutor e mestre em Letras pela Universidade Federal do Paraná (UFPR), jornalista pela Pontifícia Universidade Católica do Paraná (PUC-PR), é professor-adjunto da Universidade Tecnológica Federal do Paraná (UTFPR), onde atua em diversas disciplinas no Bacharelado em Comunicação Organizacional e no Programa de Pós-Graduação em Estudos de Linguagens (PPGEL-UTFPR). E-mail: marcelolima@utfpr.edu.br
} 
Keywords: Brazilian literatura. History. Modernity. Lima Barreto. Chronicles.

\section{INTRODUÇÃO}

A implantação do regime republicano no Brasil foi engendrada a partir de forças políticas e intelectuais orientadas pelas lógicas eurocêntricas sobre ciência, nacionalismo, economia e desenvolvimento cultural. Os anos da Primeira República (1889-1930) foram de efervescência destas forças e de seus defensores, sempre em relação direta com o capital, responsável pela transformação dos centros urbanos brasileiros, com destaque para a cidade do Rio de Janeiro. Este fenômeno é identificado como Regeneração, fazendo alusão à recuperação e ao embelezamento da capital.

Com a descentralização do poder por meio do federalismo, as elites regionais consolidaram as oligarquias via "política dos governadores", mediando as relações entre os poderes federal e local, orientadas e sustentadas pelo mandonismo, coronelismo e clientelismo. $\mathrm{Na}$ esfera federal, as oligarquias mineira e paulista se concentraram e se revezaram no poder após os primeiros governos da República da Espada (1889-1894), em que os processos eleitorais foram constituídos por fraudes e desvios.

Os conluios políticos que conduziram à consolidação do regime republicano contaram ainda com intelectuais de projeção circunstancial para o período, compondo assim a República dos Conselheiros. Eles articularam espaços de trânsito hegemônico de construção de documentos de legitimação oficial acerca da história do Brasil, da identidade nacional brasileira, como o Instituto Histórico Geográfico Brasileiro (IHGB) e a Academia Brasileira de Letras (ABL).

Para além das preocupações desta intelectualidade ligada ao oficialismo, houve o esfacelamento de uma categoria mais ampla, a dos "homens das letras" (SEVCENKO, 1999, p. 100), que se dividiu entre os que se adequavam ao novo cenário e o grupo que ficou à margem, em claro descontentamento quanto à política antidemocrática dos primeiros anos do regime republicano. Utilizando o potencial de denúncia das escritas literária ou jornalística, esses intelectuais procuraram encaminhar mudanças nos rumos do país com sua crítica empenhada Lima Barreto foi um deles. Amparado pelo serviço público que lhe garantia a sobrevivência, fez da escrita o caminho para sua ação engajada, ao publicar na imprensa e nos livros uma versão ácida do modo de vida burguês opressor, higienista e autoritário. 
Tendo em vista estas perspectivas, vamos analisar neste trabalho três crônicas do autor publicadas na revista Fon-Fon! em 1907 - vistas como narrativas históricas que articulam uma crítica à organização dos agentes políticos e o mercado, que criou uma expectativa de consumo muito além dos limites da população da época. Os textos "As paradas da "Jardim”,, “As tabuletas da Avenida" e "A propósito" (BARRETO, 2016) tratam dos impactos da organização urbana do Rio a partir da Regeneração e da introdução de diversos aspectos e práticas culturais e de consumo de origem europeia.

Para construir a análise, organizamos a exposição de forma a apresentar aspectos da trajetória de Lima Barreto, de sua formação e a relação com seus pares, e das configurações políticas, sociais, culturais e ideológicas do período.

\section{UM MILITANTE NA PERIFERIA DA MODERNIDADE}

Afonso Henriques Lima Barreto nasceu em 13 de maio de 1881 na Ilha do Governador - oito anos antes da abolição e nove antes do golpe militar que implementou o regime republicano. Impulsionado pelo pai, também funcionário público, iniciou seus estudos de engenharia na Escola Politécnica, abandonando o curso no segundo ano por falta de recursos. Foi amanuense do Ministério da Guerra, e como outros tantos escritores e intelectuais ingressou em 1903 no funcionalismo público por não conseguir se manter apenas com as atividades de jornalista e escritor. Era filho de uma professora negra liberta. Construiu uma trajetória consistente como escritor, crítico e "agitador" literário, preocupado com o registro do presente; escreveu para desmontar e denunciar as falsas relações, impressões e supostas boas intenções da Primeira República e da sociedade carioca.

Suas primeiras crônicas foram publicadas em 1902 no jornal A Lanterna, primeiro com o pseudônimo "Alfa Z" e depois assinando como "Momento de Inércia". A tônica era de crítica ao seu contexto estudantil (ele mesmo, seus colegas e professores da Politécnica) e também ao cenário político brasileiro. Seu início no jornalismo ocorreu em 1904, escrevendo reportagens para o Correio da Manhã, que posteriormente seria alvo de suas críticas voltadas à imprensa de grande porte aliada aos ditames políticos, principalmente no romance Recordações do Escrivão Isaías Caminha, publicado em livro em 1909.

As críticas ao regime republicano, às elites, aos símbolos e papéis de diferenciação e discriminação social, às ideologias violentas e enviesadas, foram orientadas com vistas a desmontar os poderes do capital, legitimados pelas práticas políticas e pelos discursos 
cientificistas. Sua farta produção de crítica social está embasada em formação intelectual sólida e na confluência de ideias e propostas de pensadores do período, de variadas orientações ideológicas: o maximalismo, o liberalismo reformista de cunho social, o humanismo russo, o racionalismo, o naturalismo, o neorromantismo, entre outras.

Para Sevcenko (1999), a preocupação de transmissão de visão de mundo nas produções de Lima Barreto tem por núcleos principais a apresentação das práticas de poder orquestradas pelas elites e também dos efeitos destas práticas, utilizando linguagem clara, condensando orientações filosóficas e literárias diversas, que corroboravam com sua trajetória de vida e seus posicionamentos diante do cenário social brasileiro, objetivando a denúncia deste Brasil invertido, em que as práticas imorais garantiam a manutenção do privilégio de alguns e a opressão da maioria.

Os efeitos do poder do capital viabilizado pelas elites políticas brasileiras, como a exclusão da população pobre, em sua maioria negra, as desigualdades sociais e raciais e o descaso do poder público com relação ao povo eram questões também presentes em suas produções de gêneros literários diversos, com intensa presença da ironia e da sátira como recurso de denúncia. A literatura era instrumento de compreensão da realidade brasileira, de crítica aos postulados republicanos orientados pela elite, que se acomodava e organizava a esfera pública para obtenção de vantagens e ganhos políticos e econômicos; também foi na produção literária que se apresentou a configuração de uma nova perspectiva de Brasil, pautada na solidariedade e no lugar de todos no mundo, com dignidade e reconhecimento da humanidade e não das posses e interesses econômicos, segundo sua perspectiva humanista.

Lima Barreto integrou um grupo de intelectuais boêmios cariocas que se reuniam em confeitarias, cafés, bares e outros espaços da capital federal e em diálogo com grupos que estavam às margens da sociedade rica e elitista - como o grupo que se reunia na casa de Tia Ciata, na Praça Onze, local do nascimento do samba, composto por músicos, poetas, malandros, candomblecistas, capoeiras, etc. Eles buscavam a troca de ideias e a fundamentação de uma literatura crítica, que utilizasse recursos humorísticos para refletir, questionar e denunciar as relações sociais das elites brasileiras: o poder político, as desigualdades sociais e a literatura produzida sob os auspícios da Academia Brasileira de Letras, a chamada literatura "sorriso da cidade". O grupo de boêmios ligados ao escritor, que se autointitulava "confraria humorística" (SCHWARCZ, STARLING, 2015, p. 341), constituía laços de apoio quase familiares.

Sob a liderança de Lima Barreto, foi organizada a revista Floreal, publicada em 1907, mas que contou somente com quatro números, provavelmente em razão de suas intenções e 
formato. A principal proposta que ensejou a criação deste periódico foi a de renovação da produção literária brasileira, possibilitando a apresentação de novos escritores, assim como de escritas que abordassem de forma crítica questões sociais brasileiras - com linguagem simples e acessível para atingir um número cada vez maior de leitores.

Editor e redator do periódico de formato e intenções inovadoras, Lima Barreto teve por inspiração a experiência adquirida no curto período em que exerceu a função de secretário da revista Fon-Fon! Ele e seu grupo de amigos viveram um período de expansão dos meios de comunicação, com significativo crescimento do número de jornais e revistas ilustradas lançados na primeira década do século XX. Essa indústria fora impulsionada pelas melhorias técnicas de impressão, reprodução e distribuição, bem como se beneficiava do aumento do interesse por informações com a formação de uma classe média que consumia hábitos e práticas culturais elitizadas, também em expansão.

É dentro deste contexto da Belle Époque tropical, com a reorganização das lógicas políticas e de acumulação de capital, formatação de novas orientações de cultura e consumo, que podemos compreender a dinâmica da trajetória de Lima Barreto, de outros escritores outsiders e da relação que estes estabeleciam com o status quo. Lima Barreto tinha posturas controversas, mas que também dialogavam de certa forma com o status quo, vide sua atuação na revista Fon-Fon! e também em Careta, em 1915 e depois, entre 1919 e 1922, ano de sua morte.

Após um primeiro momento de maior euforia de intelectuais e pensadores republicanos ou progressistas diante da expectativa criada pela Proclamação da República, o Brasil mergulhou em um período conturbado, de reorganização de forças políticas, forte repressão oficial aos movimentos sociais e revoltas civis e militares. Nesse período e diante do autoritarismo, da repressão e dos diversos processos de exclusão, forças políticas e sociais significativas passaram a compor o cenário nacional e a pleitear mudanças em diversos âmbitos, com o fortalecimento de trabalhadores urbanos e rurais com o movimento operário anarquista ou de orientação socialista, de instituições de caráter democrático e de luta por direitos para pobres e de procedimentos ligados ao regime republicano, que auxiliaram a consolidação do regime no país.

Houve intensificação da industrialização a partir deste período, com crescimento urbano em decorrência da imigração europeia e da movimentação de brasileiros pobres e libertos que saíam de outras regiões, rurais ou decadentes, para nas cidades buscarem melhores condições de vida. O Brasil teve também entre o fim do século XIX e início do XX a sua Belle Époque, 
marcada por intensa adoção de aspectos culturais, científicos e filosóficos, além de diversos produtos europeus, principalmente franceses, pelas elites brasileiras, assim como pelo poder público, a chamada “europeização” (PRIORE; VENÂNCIO, 2001, p. 269).

Dentro desse conjunto, a Regeneração foi empreendida pelo poder público para a modernização e a europeização dos centros urbanos, como a capital federal, São Paulo, Belo Horizonte e Manaus, visando a ampliação das vias públicas, a criação de boulevards e de construções amplas que reconfigurassem estas cidades nos moldes parisienses. As aberturas nos espaços do centro do Rio de Janeiro foram possibilitadas pela demolição de edificações antigas que abrigavam inúmeras pessoas, como nos casos da reorganização da região do porto e da Avenida Central. Estes projetos foram executados por meio de empréstimos de capitais de empresas internacionais que aqui se estabeleceram para prestação de serviços básicos. No plano ideológico, as transformações foram embasadas em discursos de orientação positivista e higienista, em que o progresso e a ciência conduziriam o Brasil a um lugar de destaque entre os países mais desenvolvidos e ricos do mundo.

As transformações urbanas movimentaram e aceleraram a expansão das novidades nas comunicações e nos transportes, como o telefone, o telégrafo, os bondes e os automóveis. A modernidade importada produziu mudanças nas práticas de consumo e nos hábitos das elites e das classes médias, com a introdução de novos elementos para o acesso à produção cultural: os cinemas, a moda, novos jogos e distrações, como o jogo do bicho, o futebol, etc. Estas novas dinâmicas culturais e sociais, além das mudanças nos espaços urbanos, não foram disponibilizadas para todos; o acesso foi possível a uma pequena parcela da população do Rio e de outros centros urbanos brasileiros: os espaços rapidamente foram demarcados - e aqueles considerados não pertencentes eram alvo de violência simbólica e marginalização, como no caso do próprio Lima Barreto. Os produtos culturais, símbolos da modernidade civilizatória e otimista, eram consumidos e desfrutados por poucos.

A Belle Époque, com sua proposta de embelezamento, modernização e urbanização, não tinha propósitos neutros; suas práticas discursivas deram legitimidade às intenções reformistas de higienizar os espaços dos centros urbanos e afastar os mais pobres para as periferias. Com o crescimento da população urbana, o poder público promoveu a expulsão dos pobres, em sua maioria negra, que moravam em cortiços e casarões nas regiões centrais, principalmente no Rio. As reformas foram articuladas com interesses políticos e hegemônicos de "limpeza" racial destes centros e para além dos espaços urbanos, de eliminar a população negra, considerada "degenerada" pelas teorias e discursos deterministas do darwinismo social, da mestiçagem e da 
antropologia criminal. Mulheres e homens negros, que após 1888 não foram integrados à sociedade capitalista, não receberam nenhum tipo de reparo ou indenização, substituídos pela mão de obra imigrante europeia e marginalizados pelos discursos raciais que relegaram à população negra questões relativas às doenças, ao atraso e aos problemas urbanos e sociais.

\section{NARRATIVAS HISTÓRICAS DE UM OUTSIDER}

As crônicas selecionadas para análise apareceram em 1907, quando Lima Barreto tinha 26 anos, quase concomitante à publicação das Recordações do escrivão Isaías Caminha em formato de folhetim, na revista Floreal. O autor publicou 14 crônicas no ano de 1907 em FonFon! durante o período de sua colaboração, de nove meses, sob diversos pseudônimos. Elas foram reunidas pelo pesquisador Felipe Botelho Corrêa no livro Sátiras e outras subversões (2016), e se somam a outras 150 crônicas que Lima Barreto publicou em diversos órgãos da imprensa carioca.

As três crônicas selecionadas tematizam a organização urbana do Rio de Janeiro e os movimentos da modernidade. A primeira, "As paradas da 'Jardim'”, faz um paralelo entre a criação de pontos fixos do percurso do bonde em determinado trajeto na cidade do Rio de Janeiro e as relações conflituosas entre as classes sociais na cidade, já que as paradas acabavam por privilegiar localizações que simbolizavam os valores dos estratos mais ricos da capital, "seguindo o exemplo de cidades civilizadas" (BARRETO, 2016, p. 209). Lima Barreto, em tom de conversa, típico do registro verbal da crônica moderna, toma o bonde e pontua essa organização:

\footnotetext{
Vou adiante, tomo o elétrico e sento-me no primeiro banco, banco das meditações vagabundas e que me dispensa de cerimonial quando entram as damas. As paradas começam... Que diabo! Não para em frente à Imprensa Nacional! É um sacrilégio, uma afronta, um desaforo! Não há cordão, em dia de Carnaval, que não pare diante da imprensa [...]

Mas a "Jardim" sabe fazer as coisas: anda metros e emenda a mão. Para diante do Lírico. Quem te viu e quem te vê! Ao nascer, eras um simples barracão de cavalinhos; hoje, montra sagrada das mundanidades urbanas a receber a alta homenagem de ter parada, coisa que se negou à imprensa!... (BARRETO, 2016, p. 209).
}

A parada do Lírico tem observações consideráveis, com apontamentos sobre o antigo Teatro d. Pedro II, naquele momento Teatro Lírico, onde a parada deveria ter aspectos mais chiques, mas é igual às outras. Com relação ao Passeio Público, a parada não foi posicionada 
de frente ao portão de acesso, mas mais próxima ao Cassino, um esquecimento considerável, segundo o cronista. A parada diante da Academia Brasileira de Letras leva em consideração o reconhecimento deste prédio de acordo com o sentido do bonde e de seu passageiro: para aqueles que chegam a este local vindos do largo da Carioca, não há rápido reconhecimento a respeito do prédio, mas para os passageiros que chegam ali pelo sentido Botafogo, o reconhecimento é imediato.

O cronista faz observações sobre as escolhas das paradas, e contrapõe os conhecimentos que encontra nos livros à sabedoria daqueles que organizam a cidade de acordo com a proposta de civilização. Para além, fica clara a constatação de que os bondes estão organizados para atender determinados públicos e necessidades - são os cidadãos escolhidos pela lógica elegante. Há que se observar que esta crônica é a primeira publicação de Lima Barreto na Fon-Fon!

A segunda intitula-se "As tabuletas da Avenida”, com a exposição e comentários sobre os nomes dos estabelecimentos comerciais nas tabuletas da Avenida Central, naquela época recém-aberta depois da reforma urbana de Pereira Passos. Neste texto, Lima Barreto assume mais uma vez um tom irônico, ao incorporar a voz de um narrador pertencente à elite carioca que estivesse desdenhando algumas dessas sinalizações que não estivessem seguindo as tendências do momento e elogiando outras que acompanhassem a moda: "Nos atuais tempos de transformações radicais, é bom que as tabuletas obedeçam a todas as condições de elegância, brilho e novidade; é bom também que atendam à satisfação geral, ao abarrotamento de satisfação, que enche a cidade (BARRETO, 2016, p. 216).

Mais adiante, ele reforça a tendência de a elite carioca acompanhar a modernização, ao incorporar, nas aparências, os ares de civilização dos termos da língua francesa e inglesa, que passava a ganhar espaço nos estabelecimentos comerciais brasileiros:

Há, entretanto, alguma coisa de smart. Felizmente, uma feliz reação se operou no seio dos nossos criadores de tabuleta. Café Chic! Eis aí a tabuleta que salva a nossa civilização. Todos os perigos internos e externos que porventura nos ameaçam serão evitados se formos chics, extraordinariamente chics. Sejamos chics, smarts, gentlemen, das quatro em diante, quando saímos dos escritórios e das repartições... Café chic é genial! (BARRETO, 2016, p. 217).

O uso recorrente de termos e palavras francesas e inglesas, como smart, é a expressão da modernidade carioca, segundo Lima Barreto, que atrai e empolga não pela significação, mas pela obscuridade, e com isso o autor finaliza a crônica com a proposição de instalação de uma tabuleta em hieróglifo, que resultaria em grande sucesso. A salvação da civilização está na 
tabuleta Café Chic!, enquanto o estabelecimento de nome Café Jeremias é demasiado inconveniente. As palavras chic e rosé são expressões de modernidade carioca. Estas palavras e outras: gentleman, XPTO, London; é claro o uso do recurso da sátira para a crítica ao uso em demasia das expressões e práticas culturais estrangeiras, com o encantamento manifestado pelas pessoas e observado pelo cronista sobretudo pelo desconhecimento das expressões.

A modernidade se revela oca nas tabuletas porque descaracterizada de sentido, com termos reproduzidos porque em voga e para atrair o consumo. O estrangeirismo está na moda, e adequar-se à sua dinâmica global é estar de acordo com o contexto cultural mais amplo, mas a forma como tal inserção e adequação se dão é discutível e revela a pretensão de atingir uma ligação com as nações ditas civilizadas, mas de forma superficial.

Por fim, a terceira crônica, “A propósito”, também tem como tema os bondes. O cronista faz comparações entre os elétricos que passavam por regiões mais ricas e os dos subúrbios, observando as práticas culturais distintas, permitidas de acordo com as regiões por onde circulam: vagões onde os passageiros podem fumar nos bondes dos subúrbios, ou, nas regiões do centro, vagões destinados às mulheres. Lima Barreto também compara as duas regiões, a de privilégios e a de pobreza, assim como àqueles que transitam nestes espaços, adequados a estes.

O subúrbio é a terra do sonho, sonho de outras vidas, sonho de outras idades. O subúrbio é espiritualista, quando não medieval. Se requinta, é de modo diferente de Botafogo. Este tem a visão do boulevard, enquanto aquele tem a visão dos mistérios da morte ou das justas medievais. A elegância em Todos os Santos, a suprema elegância seria andar de mortalha, chacoalhando ossos, ou senão a cavalo ajazeado e protegido, com as ferramentas pesadas. Ambos requintam, mas de modos diferentes (BARRETO, 2016, p. 342).

O cronista propõe à primeira a visão moderna, comparando-a à Paris do século XIX, e à segunda ao medievo, com batalhas e duelos, em uma perspectiva romantizada dos subúrbios, mas também direta: ao final da crônica, relaciona o amor e a morte no contexto suburbano. Utiliza, para ilustrar suas comparações, a história vivida por "um moço, rico e fidalgo de recente nobreza" (BARRETO, 2016, p. 342) que foi desafiado a algo descrito como um duelo para a disputa do coração de determinada dama, na região do Encantado; é reconhecível o traço satírico na composição da narrativa que aproxima a disputa amorosa a uma batalha de características românticas ou medievais, dois adjetivos utilizados na crônica para definir os subúrbios.

Esta relação entre amor e morte traceja, com recursos históricos e românticos, a violência presente nas áreas suburbanas, e que não é simples reflexo da organização das pessoas 
que habitam estas áreas. A comparação entre as regiões privilegiadas e marginalizadas não sinaliza uma análise mais elaborada sobre os reflexos da primeira para a configuração social da segunda, mas de acordo com as perspectivas de escrita de Lima Barreto, suas obras e demais análises, seus apontamentos políticos e ideológicos, podemos inferir que havia clareza acerca das desigualdades e opressões produzidas pelas elites, e que estes recursos textuais estão relacionados à ironia, bastante utilizada pelo autor e que se verifica presente nas três crônicas.

Tendo em vista o recorte proposto para esta análise e os apontamentos apresentados com relação a outras de obras barretianas, propomos a leitura destas três crônicas como narrativas históricas do Brasil no início do século XX. O gênero crônica tem a cidade como tema, como "personagem", como cenário e também se relaciona à modernidade, com sua configuração textual enxuta, sendo possível estabelecer relações deste formato com o imediatismo, a aceleração do ritmo de vida, da percepção temporal, da transposição mais rápida de distâncias com os meios de transporte modernos, da fotografia, do cinema, todos fenômenos da modernidade. Para os escritores, a crônica poderia viabilizar a profissionalização e o reconhecimento, a interrupção das tradições literárias e o ingresso no círculo fechado daqueles ligados à literatura canônica, que inclusive encaravam a crônica como um rebaixamento das tradições da produção literária.

Para Lima Barreto, as rupturas com a linguagem canônica e tradicional eliminou a cisão entre os âmbitos literário e jornalístico, e essa linguagem reorganizada está presente em suas crônicas e em seus romances, o que denota a versatilidade erudita e moderna do escritor. Como já observado, a relação de Lima Barreto com a modernidade e seus produtos culturais, assim como com a imprensa brasileira, é complexa e delicada, sempre dotada de forte senso analítico. O escritor foi leitor ávido de seu tempo, um flâneur, e utilizou os recursos provenientes desse contexto para sustentar suas análises, seus posicionamentos e suas perspectivas de transformação social e política para o Brasil.

Sendo o gênero crônica frequentemente associado às imagens fotográficas, podemos inferir que os textos aqui apresentados são retratos da cidade do Rio de Janeiro no início do século XX; eles tratam do contexto urbano da capital federal e das inúmeras mudanças propostas a partir de um conjunto de políticas públicas para a reorganização da cidade.

Segundo Hayden White (1994, p. 109), podemos aproximar a história e a literatura, pois "o historiador utiliza os mesmos aparatos da escrita literária para a elaboração da narrativa histórica, como os gêneros literários", que White denomina de "urdidura do enredo", compondo a operação literária junto dos dados e fontes históricas do período estudado e que resulta em 
artefatos literários. É a configuração literária, com modelos e referências da literatura, presentes no texto historiográfico, que permite ao leitor de história o reconhecimento do que o historiador propõe analisar e averiguar, espécie de modelos culturais que aproximam a narrativa histórica do leitor, que não precisa ser um especialista em história ou historiador para a compreensão do proposto.

Partindo dessa aproximação, podemos inferir que as crônicas de Lima Barreto são ficcionais e também são descrições da sociedade carioca, dos processos de análise e da relação do escritor com este contexto, possibilitando a aproximação com relação às questões discutidas ou impostas naquele período: as reorganizações espaciais da cidade, tendo o bonde como veículo de locomoção, de observação e de segregação entre centro e subúrbio (“As paradas da 'Jardim"” e "A propósito") a ampla adoção de termos e hábitos europeus e os desdobramentos sociais destas escolhas ("As tabuletas da Avenida"). Temos, com a leitura destas crônicas, o contato com a exposição de alguns dos aspectos referentes à Regeneração e à Belle Époque.

A sátira e a ironia eram recursos textuais muito presentes na escrita de Lima Barreto e de outros escritores do período, visualizados nas revistas de grande circulação, que contavam também com caricaturas e gravuras estilizadas, que davam o tom crítico aos periódicos do início do século XX no Brasil. Estes posicionamentos e práticas ilustram a percepção dos intelectuais e artistas quanto ao contexto cultural e político, sendo a sátira um recurso de análise e de ataque crítico às elites e à classe política. É com a ironia que se aponta a inversão de valores que fundamentam as práticas, em diversos âmbitos, do público ao privado, do político e relativo à formação de não cidadãos.

A literatura de Lima Barreto é veículo, instrumento de análise, de constatação e de criticidade satírica; com objetivo de atrair o leitor, produziu intensamente, usando linguagem clara e direta. Transmite uma visão de um Brasil de valores e práticas invertidos, que resultam em segregação e violências, e assim desmonta o mito da Belle Époque de modernização e civilização na capital federal. A literatura utilitária tem por missão a busca por construir situações e projeções de uma democracia que poderia tornar-se concreta, fundamentada em valores humanitários e solidários. Para Sevcenko (1999), escritores como Lima Barreto e Euclides da Cunha compreendiam a literatura utilitária e de forte senso crítico como recurso para denúncia, e como escritores-cidadãos, construíram projetos de um Estado nacional. A literatura é a história do presente, é instrumento funcional e operacional, que constrói simbolicamente o mundo; por meio da produção literária, composta por personagens e cenários abstratos, é possível relacionar e compreender questões da realidade, históricas e ideológicas, 
em âmbitos nacionais e internacionais: movimentos artísticos, literários, filosóficos, circunstâncias políticas e históricas, trajetórias e caminhos pessoais dos escritores e seus posicionamentos diante da realidade.

Corrêa (2016) aponta, em consonância às observações já feitas por Sérgio Buarque de Holanda e Antonio Candido, que a escrita de Lima Barreto "funde experiências pessoais com comentários sociais", compondo uma autoficção, fruto da preocupação do escritor em apresentar uma literatura constituída por representatividade social. Sua produção literária, portanto, não se afasta dos aspectos sociais, culturais, ideológicos do autor e em relação ao período histórico em que viveu, e pode ser entendida e utilizada como fonte histórica tendo em vista as representações que apresenta e das quais é composta.

A partir destas considerações, podemos relacionar o posicionamento de Lima Barreto com o papel atribuído ao intelectual orgânico por Antonio Gramsci (LIGUORI; VOZA, 2017, p. 430). Para este pensador, a função dos intelectuais orgânicos é de promover a construção de uma consciência crítica que relacione a teoria aos saberes e impressões que observam e absorvem a realidade, na experiência coletiva com a população, extrapolando o senso comum e mediando a relação do povo com o Estado, visando a transformação. Esta mediação visa à organização e efetivação de um projeto de emancipação social para as classes subalternizadas, em clara função operacional de condensação e formação política da população para a quebra da dinâmica hegemônica de poder e exploração. Lima Barreto é um intelectual orgânico brasileiro, e esta formação se dá a partir de sua constituição e trajetória pessoal, familiar e enquanto cidadão politizado e militante, e da relação de sua trajetória com a realidade do Brasil configurada na consolidação do regime republicano.

\section{FLÂNEUR SATÍRICO DO BRASIL INVERTIDO}

Um dos aspectos dos movimentos artísticos da modernidade mais emblemáticos está relacionado à observação feita pelo artista das multidões, das movimentações das cidades, da efemeridade espaço-temporal e cultural e ainda dos avanços tecnológicos. A figura do flâneur pode estar de certa forma afastada destas movimentações urbanas, mas as acompanha, e a produção artística da modernidade reflete as tensões, os estranhamentos e os incômodos do artista observador da galopante configuração dos tempos modernos. Tendo em vista esta breve concepção da figura do flâneur, podemos concluir que a literatura militante de Lima Barreto nos possibilita compreender os arranjos políticos e econômicos do início do período republicano, assim como os desdobramentos da Belle Époque brasileira, com suas produções 
literárias que observam, descrevem e criticam o que está nas ruas da capital federal, da pobreza crescente de muitos aos luxos excessivos de poucos.

As crônicas barretianas são narrativas históricas que apresentam o cenário urbano de uma das principais cidades brasileiras no início do século XX, com questionamentos sobre o acesso aos espaços urbanos e sobre as práticas culturais importadas e justificadas tantas vezes pela simples reprodução de modelos considerados unicamente válidos, e que resultariam no reconhecimento do país frente às nações hegemônicas. São produções literárias que utilizam modelos e recursos para a escrita e suportes culturais considerados elitizados para a publicação, mas que propõem com criticidade e humanidade novos olhares e novas percepções com relação ao país que está em construção no período e a seus cidadãos. A sátira é recurso para expor as mazelas de uma sociedade que se constituiu sobre valores e práticas individualistas e arrivistas; para além da crítica, Lima Barreto aponta caminhos, com sua produção literária, para a construção de uma sociedade mais justa.

\section{REFERÊNCIAS}

BARRETO, L. Impressões de leitura e outros textos críticos. São Paulo: Penguin Classics Companhia das Letras, 2016. RESENDE, B. (Org.)

BARRETO, L. Sátiras e outras subversões. São Paulo: Penguin Classics Companhia das Letras, 2016. CORRÊA, F. B. (Org.)

DEL PRIORE, M; VENÂNCIO, R. P. O livro de ouro da história do Brasil. Rio de Janeiro: EDIOURO, 2001. p. 269. p. 269-310.

LIGUORI, G.; VOZA, P. (Orgs.). Dicionário gramsciano. São Paulo: Boitempo, 2017.

SCHWARCZ, L.; STARLING, H. M. Brasil: uma biografia. São Paulo: Companhia das Letras, 2015. p. 318-350.

SEVCENKO, N. Literatura como missão. São Paulo: Brasiliense, 1999.

WHITE, H. Trópicos do discurso. Editora: EDUSP, 1994. 